\title{
Psychological aspects of personal safety
}

\author{
Maria A. Spihenkova, \\ Department of General and Legal \\ Psychology \\ K.E. Tsiolkovskiy Kaluga state \\ University \\ Kaluga, Russia \\ stebbins@yandex.ru
}

\author{
Artem V. Moiseev \\ Department of General and Legal \\ Psychology \\ K.E. Tsiolkovskiy Kaluga state \\ University \\ Kaluga, Russia \\ sud.exp.psy@gmail.com
}

\author{
Margarita E. Kirichkova \\ Department of Social and \\ Organizational Psychology \\ K.E. Tsiolkovskiy Kaluga state \\ University, Professional \\ communications center \\ Kaluga, Moscow, Russia \\ margaritak05@mail.ru
}

\author{
Irina P. Krasnoschechenko \\ Department of Social and \\ Organizational Psychology \\ K.E. Tsiolkovskiy Kaluga state \\ University \\ Kaluga, Russia \\ kviip@yandex.ru
}

\author{
Mariam R. Arpentieva \\ Department of Developmental \\ Psychology and Education, \\ K.E. Tsiolkovskiy Kaluga state \\ University \\ Kaluga, Russia \\ mariam rav@mail.ru
}

\begin{abstract}
The article reveals the peculiarities of psychological safety. Based on the analysis of theoretical sources of psychological safety of the person it is treated as a process, as a property of the individual and as a state. Human security in assessing dangerous situations can be defined as the ability to prevent errors that are fraught with even more dangerous consequences. In addition, it can also be defined as the ability to withstand random, unprogrammed factors, for example, the dangers that suddenly arise in an activity. Safe activity is the result not so much of counteracting a person to dangers, but rather a manifestation of his capabilities not to generate these dangers by his activities. There is also adequate and inadequate security. Under adequate protection, researchers usually mean a particular mental state of a person as an ability to withstand negative environmental phenomena or internal motivations leading to negative manifestations in activities and actions that can cause negative changes in the structure of the personality, in characterizing its features and qualities.
\end{abstract}

Keywords - personal safety, ban, personality, psychological security, aggression, hate, subjective well-being, satisfaction with life

\section{INTRODUCTION}

The modern world faces threats of transforming terrorist acts into everyday life. It is also faces threats a new world war initiated by terrorists and pseudo-democratic forces. We can talk about the transformation of mass violence in the form of wars and terrorist acts into a systemic genocide of nations and of all humankind. The comprador bourgeoisie, which lost the Second World War, is again entering to open struggle after the collapse of the USSR and the countries of the socialist camp. At the end of the XX century, comprador bourgeoisie takes revenge by deliberately destroying possible opponents. There is many victims in varying degrees of local, intense and prolonged military conflicts and terrorist acts, there is multilevel corruption pyramids, serving the interests of a small "elite" of the world's richest people. There is the demand for timely and effective provision of medical, social and psychological support to the population, its training in safety. This is particularly significant in the situation when the media of the world actively demonstrate different war stresses, catastrophes and terrorist attacks. They are engaged in intimidation of the population, carrying out orders of the comprador bourgeoisie. Due to the activation of the comprador bourgeoisie and the terrorists supported by growth of the drug business and slave-owning business, the intimidation (the formation of states of learned helplessness), disorientation (the formation of states of existential impasse and nonsense) and violence (the formation of individuals of a dangerous type) are normalizing. Due to the propaganda of the media violence and other institutions of the modern "civilized" world, violations that were formerly called posttraumatic stress disorders became normative. Now suffer not only direct victims of stressful events, but also those who observe their suffering. At the same time, we observe the indifference of states and the arbitrariness of democracy. We observe the aspiration of states and business to cash in on suffering, morally, and where it is possible and physically - to destroy people. There are other violations of the spiritual and moral, value-semantic and behavioral, interactive aspects of life of individuals and groups that prevent the spontaneous formation of personalities and "safe-type" relationships. These violations set the task of their purposeful education and training for the sake of preserving life on Earth and preserving the human community and culture $[13 ; 19 ; 30]$. The problem of ensuring the personal safety of employees of the Ministry of Emergency Situations and other professionals involved in more or less permanent military, anti-terrorist and rescue operations is of particular relevance in connection with the specifics of their professional activities. In the prevailing conditions of general social tension, the characteristic feature of modern world is the growth in the number of man-made and natural disasters, accidents. The success of the actions of EMERCOM employees in extreme situations, largely depends 
on what actions the employee took to ensure his personal safety, as well as the safety of other participants in the operation group safety), primary and secondary victims of disasters $[11 ; 15 ; 24]$.

\section{DISCUSSION}

Security refers to freedom from, or resilience against, potential harm (or other unwanted coercive change) from external forces. Beneficiaries (technically referents) of security may be persons and social groups, objects and institutions, ecosystems, and any other entity or phenomenon vulnerable to unwanted change by its environment. As a term, security is commonly used to refer to protection from hostile forces, but it has a wide range of other feeling. For example, as the absence of harm (e.g. freedom from want); as the presence of an essential good; as resilience against potential damage or harm (safety); as secrecy (e.g. a secure telephone line); as containment (e.g. a secure room or cell); and as a state of mind (e.g. psychological security). The word is also used to refer to acts and systems whose purpose may be to provide security: (e.g. security forces). Security is often defined as safety. M.A. Kotik understands the security of a person from danger, including in his professional activities, the ability of a person not to create dangerous situations, and if they arise (through the fault of the subject or independently of him) - successfully counteract them [7;8]. It distinguishes three types of security. The first type is basic security, which depends on the complex of natural psychophysiological qualities. The second type is individual security. It depends, in addition to psychophysiological, on social and professional qualities, as well as on the state of a person, his motivation, and the mechanisms of self-regulation. Human security in assessing dangerous situations can be defined as the ability to prevent errors that are fraught with even more dangerous consequences. In addition, it can also be defined as the ability to withstand random, unprogrammed factors, for example, the dangers that suddenly arise in an activity. Safe activity is the result not so much of counteracting a person to dangers, but rather a manifestation of his capabilities not to generate these dangers by his activities. There is also adequate and inadequate security. Under adequate protection, researchers usually mean a particular mental state of a person as an ability to withstand negative environmental phenomena or internal motivations leading to negative manifestations in activities and actions that can cause negative changes in the structure of the personality, in characterizing its features and qualities. Under inadequate protection is understood a special mental and personal state, implying the inability to maintain a satisfactory and realistic attitude towards oneself. It is associated with the stamina to give out their distorted desires for needs. For such a person there are deformed values and fictitious goals that it implements, despite negative assessments of society and the negative consequences of these deformations for one's own life. An example of inadequate protection is the "syndrome of war". Many symptoms of posttraumatic stress are nothing more than an attempt to protect oneself from the dangers of war, but already out of hostilities.
This attempt is connected with the experience of involvement in the suffering of other people and the internal responsibility for their destinies, which, nevertheless, is actively denied, leading a person to the brink of self-destruction. Moreover, the criterion of positivity of protection of one type or another is its actual utility for society and man. K.G. Hoyos considers the problem of security as a multilevel and multi-component social phenomenon that encompasses the tasks of management, managers, and the duties of employees, subordinates. He proposes to include in the concept of "psychology of human security" categories related to the spiritual and moral security (safety). He including in this word the civic orientation, with an understanding of the life and dignity of man, Dignity is the highest value in the existing world, it is the measures of the level of utilitarian, industrial technologies, technologies of culture (science, art and enlightenment). Concern for human dignity shows their role in the overall progress of humankind. In psychological terms, this means increasing the sensitivity of society and the state to the general pain, to personal and inter-individual responsibility for the consequences of their election actions. Security involves the sensitivity of the state to the consequences of the lack of education, lack of empathy and values, laziness and indifference, inaction and ignorance of themselves and those who are governed by state and public structure. Safety involves taking care of those who constitute the foundation of the pyramid of well-being of all and whose life force is actively destroyed in the bureaucrats struggle for power, prosperity and comfort. For a bureaucrat, a stranger's life and death mean nothing. Compared to his own well-being and success, they cost nothing. The bureaucrat is always ready to sacrifice the lives of other people. Therefore, on the one hand, bureaucracy is the best tool of the comprador bourgeoisie. On the other hand, bureaucracy is the realm in which accumulates the greatest number of psychologically dangerous individuals (ready to commit any crime for their well-being and reproduction) [1;18]. The beginning of this activity is connected with the training of special units (rescuers, ATO employees, etc.).

Modern researchers emphasize the importance of treating post-traumatic stress disorder, including through spontaneous and targeted debriefing ("sharing stories", sharing stories). They induce the state and society, ordinary "official" and "civilian" persons to understand what war is doing to people, and to wonder about what it costs. They encourage society and the population to understand what is leading to the outbreak of wars and participate in them. Scientists and practices describe the experience of soldiers and employees of special services, whose life and psyche was destroyed by the war, terrorist attacks, and their psychological consequences. Ordinary "official" and "civilian' persons can and must to understand what war is doing to people, to understand the psychological consequences of the increasing the number of psychologically dangerous individuals (ready to commit any crime for their well-being and reproduction). They do not stop at short-term effects, but follow their respondents "home", into the "ordinary" world, examining their sufferings in this ordinary 
but also violent world. These works often indicate a deep desire to heal (profound desire to heal): respondents, "ordinary" citizens, themselves and the world. This is a difficult material, as many of the points discussed in these studies are frankly cruel, revealing deeply intimate aspects of losses from wars, terrorist attacks and emergencies on a personal, personal level. Discussing "things that special services and servicemen" cannot say, researchers and researchers demonstrate a rare courage, for them truth means something completely different from for ordinary people. An example is head injuries that deprive the ability to empathize and to love. An example is an attempt to rethink the murder of an innocent person. An example is their involvement of the person to the murder, his indifference and lack of help. An example is respect for the enemy who tried to kill you. An example is also may be complicity to the murder and the search for redemption, capable of saving the man from the self-destructive downward spiral [29; 31]. In itself, understanding the "spirality" of violence, understanding the need for search, redemptive and volitional exit from violence is the main motive of these theoretical and practical studies. The clash with death, even accidental, and even more so the consciousness of one's own participation in the murder, is not customary in the ordinary world. But it's necessary and necessary to talk about and it's just necessary: terrorism came into the life of countries that never thought that someone would once encroach on their peace of mind. To investigate and correct what is happening is the only way to survive a war, a terrorist act or a catastrophe, to start a new, truly peaceful, that is, a safe life: without nightmares, drugs, etc.

One of the central tasks in training and rehabilitation of special services officers is the upbringing and restoration of the "personality of a safe type" - which cannot only survive in dangerous situations, but can also help survive to others. Security should be linked to other values (morality, responsibility, health) and, along with them, should have a pronounced and conscious "personal meaning" for the individual, acting as a condition for preserving both one's own life and mental health, and the life, health of the victims catastrophes. The professional attitude to risk is provided by understanding of rescuers the meaning of their work: only under this condition risk readiness does not become a desire for rash risky actions, dangerous not only for the "rescuer", but also for other people involved in the extreme situation. It is necessary to understand and comprehend the personality of the fact that everyone's safety is closely linked with the preservation of the somatic and mental health of others. The safety of others, society as a whole, thus, is a function of observing the rules of personal security. That is why the role of the psychologist in the work of special services is so great and in the process of rehabilitation of primary and secondary victims of extraordinary events, disasters and terrorist attacks, wars: specialists and civilians who have fallen victim to the multi-level pyramid of violence typical of many "democratic" countries.

Help them related to the treatment of the prevention and correction of psychosocial aspects of disorders and diseases, especially - diseases and mental disorders that have arisen in connection with the experience of various events that traumatize the psyche and the body as a whole. A vivid example of such events is participation in military operations, refugee, hostage and torture, arbitrariness and corruption, stalking and bullying of the population by law enforcement, educational, medical and other state and public structures. A vivid example of such events is also participation in the liquidation of the consequences of terrorist acts and disasters, caused by both natural cataclysms and illiterate management of production processes, and deliberate use of bioclimatic and other types of weapons of mass destruction etc. Another example is the constant stay in countries whose government is supported by nationalist and frankly fascist regimes - in which people are divided into "citizens', "separatists" and "temporarily residing": people live in a state of constant threat of mass violence and persecution, as well as in the state of constant violence against them by the authorities. In the territories of mass "congestions" of such "separatists" unannounced wars are conducted, systemic stalking and bullying of dissidents are organized, who do not want to destroy fellow citizens and even those who are afraid of persecution are trying to leave the country $[3 ; 4 ; 17]$. Specialists conducting rehabilitation and preventive measures deal with a combination of mass and individual, past and current violence by the surrounding and the state, multiple transcending traumatic events in which people act both as objects and as subjects of violence $[9 ; 17]$. At the same time, the real picture is so complicated and complicated that simple methods such as "dog-dog-death" cease to work: waves of violated law, supported by the governments of these countries, smoothly replace each other, and those who became their victims often self-destruct without waiting for "triumph of justice". However, traumatic events are only part of the overall picture, an external circumstance that has or continues to play a role in the painful process, but often only masks the true drama of human beings from Ocean. The external event, however brutally it was, always overlays on internal circumstances, including the knowledge and skills of a person to behave productively towards violence. This knowledge and skills can be called a "culture of violence" or "competence in relation to violence". They include victim competence (protection from external and internal violence) and competence in the implementation and termination of violence (knowledge and skills in the field of punishment, their prevention, implementation and completion of penalties). The least developed moments of this competence are protection from internal violence (self-punishment and autodestruction in general) and knowledge and skills in the field of prevention and cessation of violence. Humankind has for centuries practiced in the implementation of external and internal violence, not being able to solve the question of its essence, as well as its processes and results, opportunities and constraints. The experience of wars and terrorist acts to resolve this issue actively encourages both to help the victims of wars, and to avoid wars as such. Most veterans of military operations, who have experienced multiple trans-ordinary events associated 
with mass deaths and death threats, treachery and deprivation, a complete violation of human rights and moral relations, are characterized by similar violations of internal equilibrium. This special complex of psychological problems was given the medical name "military (war) stress" or, later, "post-traumatic stress syndrome". In the case of wars with the "separatists", a person who has encountered the contradiction of the reluctance to kill and the need to kill, and who resolved this contradiction in the direction of the "desire to kill", as a rule, absorbs another disorder that involves total alienation from one's own humanity. Conscious of their actions as purposeful actions to achieve in varying degrees general, military goals, these people are not able to assess their spiritual and moral meaning, to assess themselves as subjects who realizes these actions in terms of compliance with this meaning. The phenomenon of duality or doubling of personality becomes a frequent phenomenon - both victims and persecutors [19]. A destructively directed, dangerous person and the surrounding personality is formed in specific conditions. Doubling allows you to survive in extreme situations. Collisions of this level are healed for a long time. They are healed rather in the practice of spiritual and religious help. Psychological, medical or social assistance are less effective and productive. They are described, for example, as an obsession that is overcome through the mechanisms of service, penance and penance. In classical psychiatry, medicine and psychology, these conditions are described and studied much less "posttraumatic stress disorder": from a social point of view, militants and other representatives of a group of people who desire and enjoy killing and raping, persecuting and poisoning others, are subject to "destruction": work with military and other "official" criminals in fact, is not expected. At the same time, the essence of the violation (the refusal to be a person) remains outside the attention of specialists. At the same time, the consumer society, which has become a label of modern "civilization" that extols anomie and tolerance, physical and social well-being, is the basis for the formation of what can be called social cannibalism. Beginning as a desire and pleasure to destroy oneself in competition for survival and reproduction, He leads to a refusal to recognize them as people. The final stage of the violation is the refusal to consider himself a person.

This disorder, which is called M.R. Arpentieva a "protraumatic stress disorder", is similar to the symptoms of self-damaging behavior. It can be assumed that it is a form of compensation for the states of helplessness and impotence experienced and experienced by a person throughout his life: from early childhood to adulthood. Not being able to escape from violence, a person creates its endless "cycles" or "spiral". The spiral of violence, unwinding, involves all the new participants, including those who fulfill the functions of the "final situation" for the one who activated it. In fact, protraumatic stress disorder is aimed at self-destruction of a person and those around him. Post-traumatic stress, on the contrary, is the survival of a person and those around him. In the protraumatic stress disorder, therefore, the goal itself and the accompanying value-semantic aspects of the experiences and actions of the personality are distorted. In post-traumatic are violated (not so much targeted) value-semantic or "psycho-technical" aspects of human experiences and deeds. Post-traumatic stress is overcome, therefore, through the awareness of the person and support surrounding his awareness of the goal of experiences and deeds in the transordinal and post-transordinal situation ("survival") [9; 23]. Protravmatic stress disorder is overcome through the total transformation of the basic meanings of human life. Unfortunately, such a transformation is often impossible: in the aid of such a person, neither the state, nor the experts, nor the person himself, who is easier to die than to change, can be unprepared and unmotivated. In addition, a number of survivors of protraumatic stressful events quite safely continue to live after them: the consumer society with its anomie and pseudo-tolerance is the optimal environment for life that does not induce a person to repent and does not set him any other tasks than those he used to put: survival at the expense of other people. Perhaps this is the secret of little scrutiny of such violations and their carriers: the beginning of the studies of bullying (baiting) and "stalking" (persecution) are too fragmentary to comprehend the whole scale of the violence, even on the example of an individual person or group. Until such time as the question of the ubiquity of violence and the culture of violence is raised, so long as violence relies on the "legitimate attribute" of power and "illegal attribute" in the relations of people not included in it, wars, terrorist acts and other forms of mass and individual violence under various pretexts, will flourish. The central point of the rehabilitation of man and society as a whole is the realization of the essence of violence in human life, its role in the development or destruction of the individual's self-awareness. M. Blanchot writes: “... between a normal person, driving a sadist into a dead end, and a sadist who turns this dead end into an outlet, is someone who knows more about his true position and has a deeper understanding of him. So he is capable to help a normal person to realize himself, assisting him in changing the conditions of all comprehension" [6]. A protraumatic stress disorder includes the whole complex of consequences and causes of violence towards oneself and the world: the subject of a protraumatic disorder is both a victim and a persecutor. It is with this connected phenomenon like "Stockholm syndrome": incompetent, but an attempt to understand the criminal hostage, find a common language with him and even help - to survive, despite his own desire to destroy - the world and himself. It is important that due to the psychological trauma, prejudices and negative experiences inflicted on the victims of war and war criminals, the ability to adequately analyze the conflict situation from different sides is often lost. Everyone explains his actions from his "point" of the beginning of the conflict as a response to the actions of the other and everyone considers himself right and a victim of another's aggression. For the person traumatized by the situation, the desire for revenge and punishment or for avoiding punishment and reciprocal accusation becomes dominant. The situation as a "black hole" pulls consciousness into a "painful point" with the desire to justify itself, take 
revenge, pretend that nothing has happened, etc., that he and others are not people (not worthy people), etc. In order to understand, we need an outsider who creates a space in which people can regain control over conflictual relationships: someone close and respected people or a specialist who leads programs for restorative resolution of conflicts and criminal situations. Until the changes in the "understanding space" have occurred, it is difficult to expect real changes in the "decision-making space". The offender and the victim, even if they are not even familiar, can suddenly find themselves in a special kind of situational interaction. This situational interaction makes it possible to dig not only the secrets of internal and external wars and their experiences, but also those secrets of the soul that lie at their base. Recognition and reconciliation are based on unconditional respect for human life, human relationships and society, spiritual, and not only material, long-term and immanent, not only casual and shortterm communication of people, taking into account religious, cultural, political differences in lifestyles. Both parties can influence each other directly, getting a chance to resolve the conflict that arose because of the wrong erroneous behavior (act) of one or both parties. The ideal result of rehabilitation work in couples "victims - criminals" consists of two steps. First, the transgressing laws of man and God expresses shame and sincere repentance in their actions. Then - the victim in return takes, at least, the first step towards his forgiveness. These two steps are "restorative actions", they contribute to the re-creation of the relationship between the victim and the offender, between nations and countries, destroyed by crime. Without "restorative action" whatever agreement is reached, it does not reduce tension and leaves the participants with a feeling of dissatisfaction, the roots of the violation remain untouched $[1 ; 2 ; 5 ; 20 ; 21 ; 26 ; 27]$. The development of humankind implies, among other things, a culture of attitude towards violence (culture of violence). This is ability to help those people, who in the modern world become a criminal, without the chance to change and realize what they have done. This is also the ability to overcome the consequences of violence for "victims" and "criminals" and develop a secure relationship. This is also the ability to devoid of violence, the ability to shaping or restoring a safety in inner world and in interpersonal relation. Awareness and change are possible where the culture of violence is formed: an understanding of violence inevitability and its functions instead of meaningless taboos at any discussion of the reality. The culture of violence is the understand of its inevitability in the system of human relations, the awareness as an abnormal desire to cause pain and enjoy the suffering of the innocent. Just like the death instinct, the "instinct of violence" must and can be realized and transformed, including socially approved forms. Society and the victims of wars and catastrophes need the opposite: a sincere, realistic understanding of what happened and the acceptance of the experience of violence and its consequences - in themselves and others. The cycle of violence can be opened: not only victims need help, but also "persecutors", and, as research and practice of debriefing - "rescuers" [6] show. Restorative work, thus, includes procedures for the formation and reforming of the culture of violence of the individual and the group (community). Conclusion Long stay and activities in extreme conditions lead to depletion of the person's psychological resources. Conditions of shortage of resources of psychological protection lead to an increase in aggression. Due to its reactive nature, aggression is easily activated by propagation [14]. Therefore, the help in healing is not in itself (re) the adaptation of a person who has become dangerous to himself and others, to ordinary social norms. The help in healing is the help the person to reconcile himself and himself, to see himself as he is at the very and, making changes in their lives, not ignoring mistakes and crimes against themselves and against the world. This is help to live with accordance with life, opening new opportunities and prospects, through their own security to create the safety of life them. Finding the world in your own soul allows a person to discover new, more adequate and adaptive ways of protecting against traumatic events and ways of coping with difficult experiences and stresses. Open the cycle of violence and defend against it in the future. Huge experience of working with people who survived crisis is accumulated in the works of practical psychologists dealing with psychological and physical (including sexual) violence, problems of psychological survival and personality transformations related to the person's stay in the war zone, participation in them. Huge experience is accumulated in the working with people who have endured lethal diseases (cancer, etc.). In any of these cases, there is a universal pattern: the need to separate the "spheres of influence" of an objective (physical, external) threat or traumatic situation and a zone that is subject to potential control on the part of the person himself, which requires forgiveness and correction and cannot be corrected $[10 ; 12 ; 14 ; 16 ; 22 ; 28 ; 29]$. The productive rethinking of traumatic experience, the transformation of posttraumatic and protraumatic stresses suggests a significant change in the temporal perspective of its analysis: a reorientation from searching for objectively nonexistent internal causes (past) that occurred to build models of the future, with "Why?" On "For What?"

\section{RESULTS}

Modern researchers emphasize the importance of treating posttraumatic stress disorder, including through spontaneous and targeted debriefing ("sharing stories", sharing stories). They induce the state and society, ordinary "official" and "civilian" persons to understand what war is doing to people, and to wonder about what it costs and whether to start wars and participate in them. They induce the state and society to investigate the experience of soldiers and employees of special services. Life, health and the psyche of those people was destroyed by war, terrorist attacks and catastrophes, their psychological consequences $[1 ; 4 ; 20 ; 21 ; 27]$. They do not stop at short-term effects, but follow their respondents "home", into the "ordinary" world, examining their suffering in it ordinary, but also a violent world. These works often indicate a deep desire to heal (profound desire to heal): respondents, "ordinary" citizens, themselves and the world. 
This is a difficult material, since many of the points discussed in these studies are frankly cruel, revealing deeply intimate aspects of losses from wars, terrorist acts and emergencies on a personal, personal level. Discussing the things that special services and military personnel often simply "cannot say ", even to themselves and to the nearest, not to mention society and the state, researchers and investigators discover amazing courage. For those people "truth" means something completely different from for ordinary people. Head injuries that deprive them of empathy and love are an attempt to rethink the murder of an innocent person and their involvement in murder, their indifference and lack of help. This is respect of the winner in relation to the enemy who was previously trying to kill him. This is their complicity in the murder and the search for redemption, capable of saving from the self-destructive downward spiral $[29 ; 31]$. In itself, understanding the "spirality" of violence, understanding the need for search, redemptive and volitional exit from violence is the main motive of these theoretical and practical studies. The clash with death, even accidental, and even more so the consciousness of one's own participation in the murder is not customary in the ordinary world. But it's necessary and necessary to talk about and it's just necessary: terrorism came into the life of countries that never thought that someone would once encroach on their peace of mind. For those who do not parting with the war the war is a very difficult and traumatically experience in past, present and future. The war in his internal world is continue. For those who returned from the war both in psychological, inner and in physical, external sense the war is not only difficult and traumatically experience, this is a school of real life, understanding of the life and himself. Behind their back is death, which can sometimes be impossible to get rid of. The person seems to have no place in the world for love and faith, faith in destiny and fate, in life and in God. Violence and danger, overstrain and the experience of deaths and murders do not pass without a trace: the war "settles" inside [9; 17]. To investigate and correct what is happening is the only way, after surviving a war, a terrorist act or a catastrophe, to find peace and start a new, truly peaceful that is a safe life: without nightmares, drugs, etc. Human security is the name of an emerging paradigm which stressed "the right of people to live in freedom and dignity" and recognized "'that all individuals, in particular vulnerable people, are entitled to freedom from fear and freedom from want with an equal opportunity to enjoy all their rights and fully develop their human potential" [32, p. 31]. Recently in psychology was proposed the concept of vicarious retribution. It means aggression directed to person or group that didn't do something wrong to agent of aggression but harmed to ingroup in the past. This violence can be defined as hate crimes and presuppose hatred and hostility to a target group's representatives for their social belonging only [33; 34, p. 2193; 35; 36]. "Researchers of terrorism believe that often very talented youngsters who had been discriminated against solely because of their social background became involved in these terrorist groups" [37]. Scientists wrote, that many atrocities, including massacres and collective violence in war and outside the framework of war, is impossible understand without the concept of hate [38]. Some hate crimes could be understand by vicarious retribution based on hate (by resentment, contempt and "negative stereotypes"). The target of hate is understood as powerful and "irrationally influential": there are cultivated hate, inside particular social norms and standards, and hate outside such norms that has no rational basis in real life. Both types of hate could arouse tragic consequences through brutal violence (in regular or irregular military conflicts and explosions of violence). The target of hate arouses strong and frequent anger reactions of haters [39]. Ruminations about resentments are directly or ambiguity correlated with inclination to hostility and aggression [40]. While the passive hate is manifested by escaping and distancing only, the active hate is manifested by condemnation and trying to harm the target of hate including physical violence. In comparison of adolescents in adults active hate significantly decreases, but there is no differences in passive hate [34].

\section{CONCLUSION}

A psychologically safe person is a person who is satisfied with his own life, with himself and with the world. This person does not need the desire to hate others, conceal insults and seek revenge. This person has realized himself. He is able to efficiently and efficiently process stressful situations, accumulating experience of forgiveness, freedom, transformation and adoption of transformations. A secure person possesses a high culture of violence, realizing that it is not avoidance, but not trying to justify it either by one's own or by others' actions, by suffering from intentional cruelty and murder.

\section{REFERENCES}

[1] M.R. Arpentieva, "Restorative justice: features and perspectives", in . Advisor to the lawyer, 2015, vol. 9, pp. 3-11. (In Russian)

[2] M.R. Arpentieva, "The doctrine of understanding and the activity of a social worker in juvenile justice", in Advisor to the lawyer, 2015, vol. 10, pp. 58-76. (In Russian)

[3] M.R. Arpentieva, "Modern fascism and social service", in Bulletin of K.E. Tsiolkovskiy Kaluga State University, 2015, vol. 2, pp. 30-46. (In Russian)

[4] T.F. Zolotareva, M.R. Minigalieva, "Problems of social and psychological assistance to the victims of terror" Moscow: Publishing House "Soyuz", 2002, 256 p (In Russian)

[5] O.V. Krasnova (ed.), "An anthology of hard experiences: sociopsychological help: Collection of articles". Moscow, Obninsk: The Printer, 2002, 336 p. (In Russian)

[6] M. Blancho, Sad. "Marquis de Sade and the twentieth century. Comp. V.V. Ryklin. Moscow: Culture, 1992, pp. 47-88. (In Russian)

[7] M.R. Arpentieva, "Psychological aspects of law enforcement: an essay on legal psychology". Kaluga: K.E. Tsiolkovskiy Kaluga State University, 2017, 270. (In Russian)

[8] M.A. Kotik, "Psychology and safety". Tallinn: Knowledge, 1981, 320p. (In Russian)

[9] M.Sh. Magomed-Eminov, "The existential situation of the survivor", in Proceedings I All-Russian Scientific and Practical Conference on Existential Psychology. Moscow: Sense, RPO, 2001, pp. 35-36. (In Russian)

[10]T. Nchols Global overview of human response to natural disasters: earthquakes. Natural disasters: study and methods of struggle. Ed. G. F. White. Moscow: Progress, 1978, 440p. (In Russian) 
[11]M.A. Padun, A.V. Kotel'nikov, "Mental trauma and the picture of the world: Theory, empirics, practice", in. M.A. Padun. Moscow: IP RAS, 2012, 206p. (In Russian)

[12]L.A. Pergamenschik, N.L. Puzyrevich, "Psychological help in crisis situations. Workshop". Minsk: Publishing House Grevtsova, 2012, 340 p. (In Russian)

[13]V.E. Popov, "Psychological rehabilitation of servicemen after extreme impacts. Diss ... cand. psych. Sciences". Moscow, 1992, 20 p. (In Russian)

[14]. P.M. Mazurkin, "Prevention, rescue, assistance: Materials of scientificpractical. Conf., Jan. 12, 2000". Yoshkar-Ola: Mari State. Technical University, 2000, 107 p. (In Russian)

[15] Shoigu Yu. S. (Ed.) "Psychology of extreme situations for rescuers and firefighters". Moscow: Sense, 2007, 319 p. (In Russian)

[16]B.A. Smirnov, E.V. Dolgopolova, "Psychology of activities in extreme situations". Kharkov: Publishing house of the Humanitarian Center, 2007, 292p. (In Russian)

[17]Flier A.Ya. "Cultural causes of violence", in Knowledge. Understanding. Skill, 2012, vol. 1, pp. 19-25. (In Russian)

[18] Khoyos K.G. "Psychology of security in place of the traditional problem of accident", in Foreign psychology, 1995, vol. 3, 5, pp. 45-56. (In Russian)

[19]L.S. Austin, L.S. Godleski, "Therapeutic approaches for survivors of disaster. Psychiatric Clinics of North America, 1999, vol. 22, 4, pp. 897910.

[20]J. Braithwaite, " Crime, Shame and Reintegration". Cambridge. UK: Cambridge University Press, 1998, 236p.

[21]R.A.B. Bush, J.P. Folger, "The Promise of Mediation Responding to Conflict Through Empowerment and Recognition". San Francisco: Jossey-Bass, 1994, 320p.

[22]L.M. Davidson, A. Baum, "Chronic stress and post-traumatic stress disorders", in Journal of Consulting and Clinical Psychology, 1986, vol. 54, pp. 303-308.

[23] Diregrov A. Caring for helpers in disasters situations psychological debriefing. Disaster management, 1989, vol. 2, pp. 25-30.

[24] "Disasters Working Party", in Disasters: Planning for a caring response. Part 1,2. London: Bernan Press, HMSO, 1992, vol. 230, pp. 240.

[25]A. Dyregov, "Caring for helpers in disaster situations", in Disaster Management, 1989, vol. 2, pp. 25-30.
[26]Ez. Fattah, "Towards a victim. Victims of crime". Eds. by A. J Lurigio. Thousand Oaks, CA: Sage, 1997, pp. 7-25.

[27] L. Gold, "Influencing Unconscious Influences The Healing Dimension of Mediation", in Mediation Quarterly, 1993, vol.11 (1), pp.55-66.

[28]R. Hodkinson, M. Stewart, "Coping with catastropha. A handbook of disaster management". London, New York: Routledge, 1991, 271p.

[29] Sites K. "The things they can not say", in Stories soldiers will not tell you what they've seen, done or failed to do in war. New York, London, Toronto, Sydney, New Delhi, Aucland: Harper Perennial, 2013, 336p.

[30]R.J. Ursano, C.S. Fullerton, K. Vance Posttraumatic stress disorder and identification in disaster workers. American journal psychiatry, 1999, vol. 156, 3, pp. 353-359.

[31]Zehr H. "Changing Lenses" Scottdale, PA: Herald Press, 2015, 302p.

[32] United Nations General Assembly . "Resolution adopted by the General Assembly 60/1: World Summit Outcome", in United Nations, 2005, vol. 24 October, pp.1-38

[33] W. Cheng, W. Ickes, J. B. Kenworthy, "The phenomenon of hate crimes in the United States", in Journal of Applied Social Psychology, 2013, vol. 43 (4), pp. 761-794.

[34] G. Breslav, "Psychological Security of Two Generations in Latvia", in Journal of Siberian Federal University. Humanities \& Social Sciences, 2014, vol. 12, pp. 2191-1204.

[35]B. Lickel, N. Miller, D.M. Stenstrom, T.F. Denson, \& T. Schmader, "Vicarious Retribution: The Role of Collective Blame in Intergroup Aggression”, in Personality and Social Psychology Review, 2006, vol. $10,(4)$, pp. 372-390

[36] W. Michener, "The Individual Psychology of Group Hate", in Journal of Hate Studies, 2012, vol. 10 (1), pp.15-48.

[37] McCauley, C. R. \& Moskalenko, S.. "Friction: Radicalization Happens to Them and Us". New York: Oxford University Press, 2011, 248p.

[38]R. J. Sternberg, \& K. Sternberg, "The Psychology of Hate". Washington, DC: American Psychological Association (APA), 2008, 263p .

[39]D. Bar-Tal, "Collective memory of physical violence: Its contributions to the culture of violence". In G. Salomon \& B. Nevo (Eds.), Peace education: The concept, principles and practice around the world. Mahwah, NJ: Erlbaum, 2002, pp. 27-36.

[40]M. D. Anestis, J. C. Anestis, E. Selby, T. E. Joiner, "Anger rumination across forms of aggression", in Personality \& Individual Differences, 2009, vol. 46 (2), pp. 192-196. 